\title{
Patterns of Sponge Abundance Across a Gradient of Habitat Quality in the Wakatobi Marine National Park, Indonesia
}

\author{
Abigail L. Powell ${ }^{*}, 1$, Leanne J. Hepburn ${ }^{2}$, David J. Smith ${ }^{2}$ and James J. Bell ${ }^{1}$ \\ ${ }^{I}$ Centre for Marine Environmental and Economic Research, School of Biological Sciences, Victoria University of \\ Wellington, P.O. Box 600, Wellington 6140, New Zealand \\ ${ }^{2}$ Coral Reef Research Unit, University of Essex, Wivenhoe Park, Colchester CO4 3 SQ, United Kingdom
}

\begin{abstract}
Sponges are important components of reef communities worldwide, fulfilling a number of important functional roles. Habitat degradation caused by the loss of hard corals has the potential to cause increases in sponge abundance and percentage cover as they gain access to resources such as space and food. In this study we compared sponge densities and percentage cover at sites with varying hard coral cover in the Wakatobi Marine National Park, Indonesia (WMNP). We found significant differences in sponge densities at the study sites but no significant difference in sponge densities on different surface angles. Unexpectedly, we also found a weak positive correlation between coral cover and sponge density. This indicates that spatial competition is unlikely to be the most important factor determining sponge abundance in the WMNP. In contrast to sponge density data, we found that sponge percentage cover and hard coral cover were weakly negatively correlated, but found no significant difference in sponge percentage cover between the study sites. Finally, multivariate analysis of the benthic communities at the study sites indicated that while sites with higher coral cover were characterised by coral (proportionally), lower coral cover sites were characterised by algae and sponges. This suggests that although there was no significant difference in sponge percentage cover between the study sites conditions that led to the loss of hard coral at lower quality sites mean that these sites are characterised by sponges and algae rather than by any other groups of benthic organisms.
\end{abstract}

Keywords: Sponge ecology, sponge distribution patterns, Porifera, Sulawesi, reef invertebrate assemblages, coral reef degradation.

\section{INTRODUCTION}

In addition to their exceptional biodiversity, coral reefs contribute to coastal protection, and are a vital source of income and food for nearly 500 million people worldwide [1]. Coral reefs across the globe are currently declining as a result of many threats including overexploitation, habitat destruction, increased sedimentation and nutrient levels due to poor land management, and face the potential future threats of ocean acidification and raised sea temperatures as a result of climate change [2-4]. One of the key consequences of habitat degradation is the loss of reef building corals and subsequent reduction in physical complexity. Topographic diversity, a key characteristic of tropical coral reefs, is one of the main drivers of biodiversity and therefore degradation leading to a loss of hard corals will have major and long lasting detrimental impacts on ecosystem diversity and productivity [2,5]. Currently, much research focuses on investigating and mitigating the impacts of hard coral loss on reefs [6-8], however, the vast majority of this research does not take into account a major component of coral reef communities; sponges.

Sponges are extremely widespread occurring in marine environments from polar to tropical regions [9-11]. Porifera,

*Address correspondence to this author at the Centre for Marine Environmental and Economic Research, School of Biological Sciences, Victoria University of Wellington, P.O. Box 600, Wellington 6140, New Zealand; Tel: +64-4-4635339; E-mail: abigail.powell@vuw.ac.nz as key spatial competitors, are integral components of tropical coral reef systems and play several functional roles including nutrient cycling, reef consolidation, bio-erosion, facilitating primary production and bentho-pelagic coupling $[12,13]$. Abundance and spatial distribution of sponges are influenced by both physical factors, including substrate angle, offshore distance, depth and sedimentation $[10,14$, 15] and biological factors including competition and predation $[16,17]$. The relative importance of biological and physical factors in driving sponge abundance patterns is still unclear but could have far reaching implications when attempting to predict the impacts of environmental degradation on sponge assemblages. For example, if sponges compete with corals for resources such as space and food, a decline in coral abundance could result in an increase in sponges with subsequent ecosystem function effects. In contrast, if sponge abundance and diversity patterns are primarily driven by physical factors then changes in coral abundance will have little effect on sponges.

Previous studies have shown that sponges are important spatial competitors in temperate and tropical benthic communities $[16,18]$. Most information regarding sponges as spatial competitors on coral reefs comes from the Caribbean where sponges use a number of mechanisms to compete for space including, the production of toxic secondary metabolites $[19,20]$, variable growth rates [21] and variable growth forms [22]. Comparatively, little information is available for other coral reef regions. In Indonesia, de Voogd et al. [23] found that four sponge species use bioactive compounds to 
a.

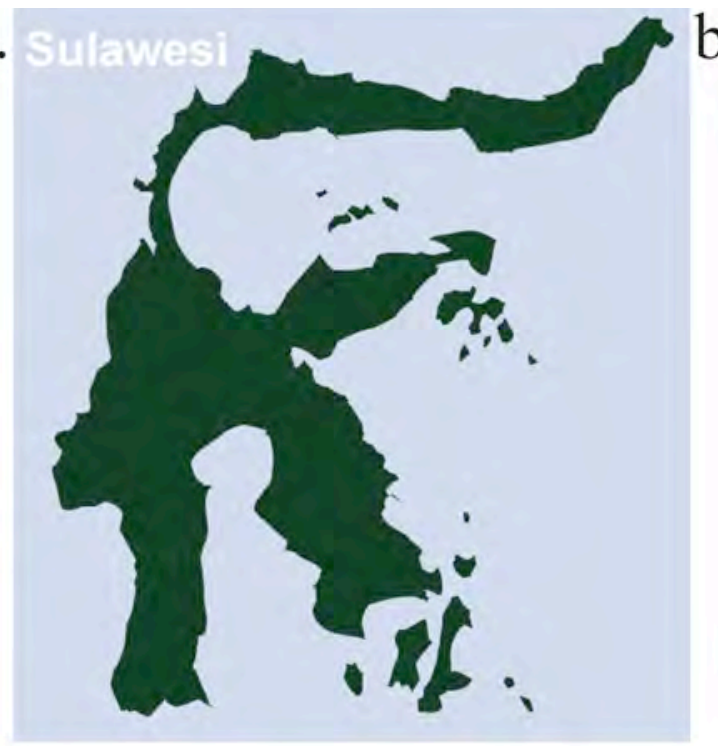

b.

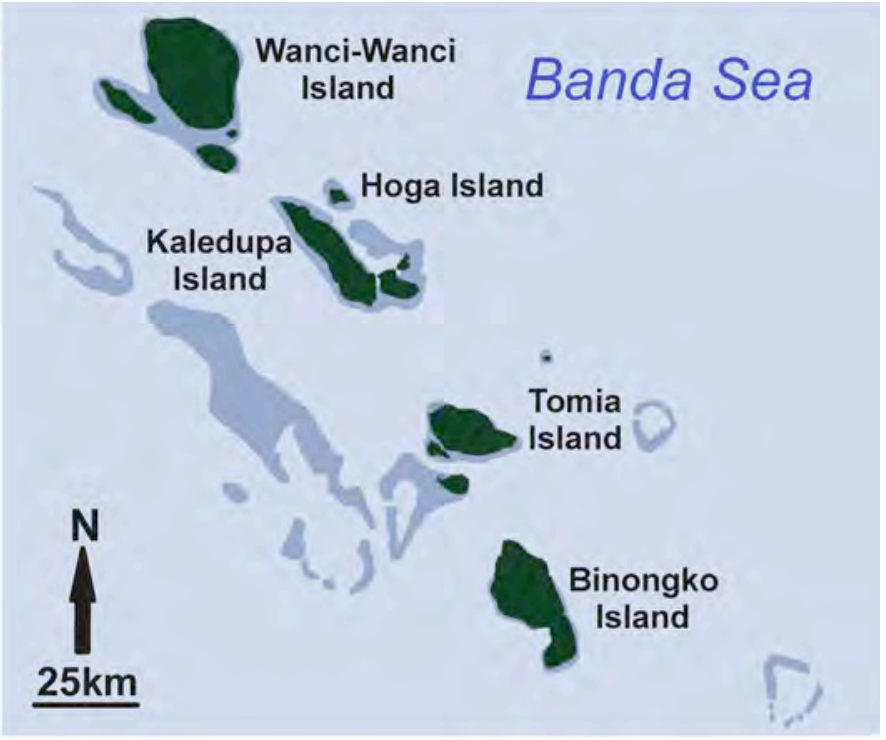

c.

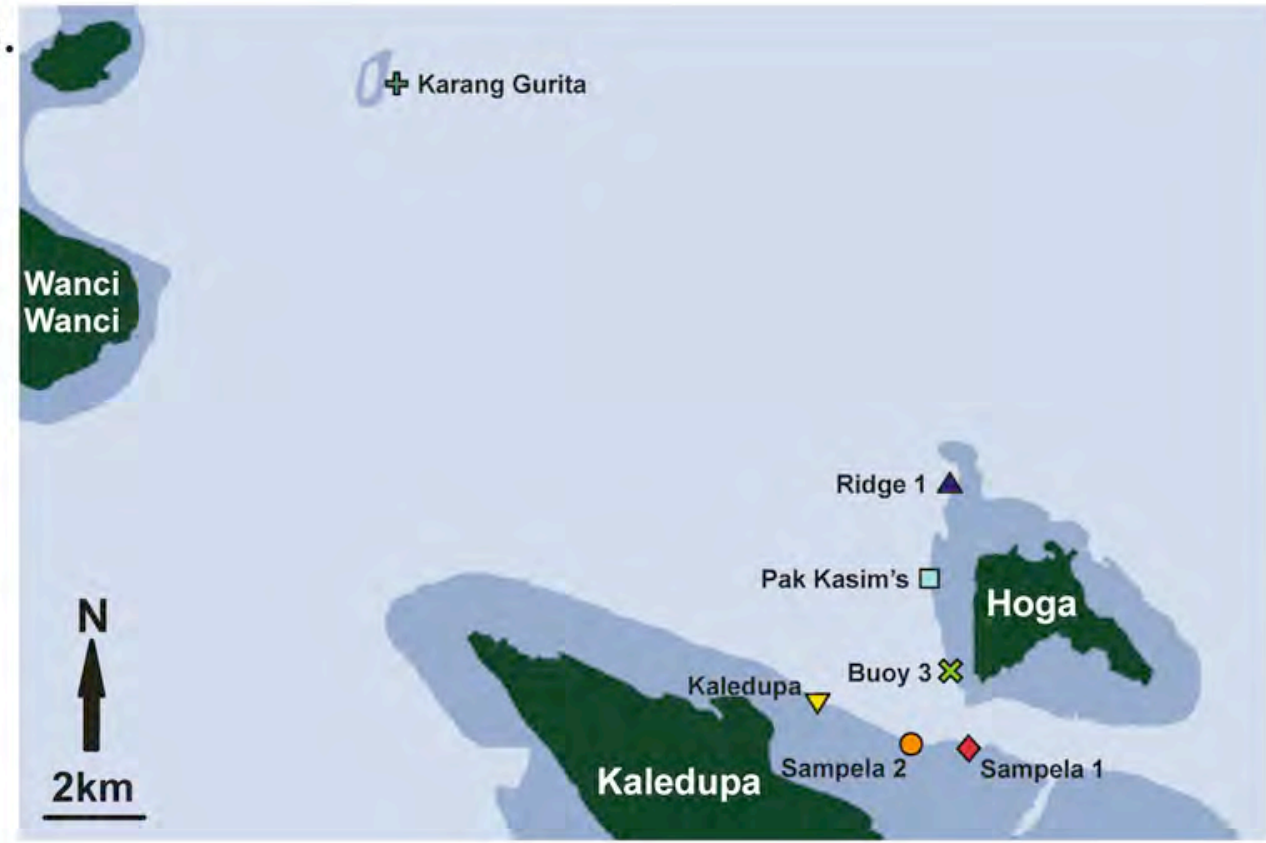

Fig. (1). a) Map of Sulawesi b) The location of Hoga Island in relation to the other main islands of the Wakatobi: Wanci-Wanci, Kaledupa, Tomia and Binongko islands $\mathbf{c}$ ) The location of the seven study sites.

compete with corals in the Spermonde archipelago in Sulawesi.

In this study we attempt to examine spatial relationships between sponges and hard corals to see if competition is likely to be a major factor driving sponge abundance in the Wakatobi Marine National Park (WMNP) SE Sulawesi, Indonesia. Rather than focusing on the competitive abilities of a few species we carried out surveys of sponge abundance at a number of sites with different levels of hard coral cover as a result of habitat destruction. Previous work in the Wakatobi has indicated that surface angle may influence sponge density at some sites so surveys were carried out on flat, inclined and vertical surfaces [14]. We hypothesise that sponge densities and percentage cover will be negatively correlated with coral cover as sponges will be released from spatial competition with hard corals. In addition, we hypo- thesise that sponge densities will be affected by substrate angle with higher sponge densities occurring on vertical, inclined and horizontal surfaces respectively.

\section{MATERIALS AND METHODOLOGY}

\section{Study Sites}

The WMNP comprises four main islands, Wangi-Wangi, Kaledupa, Tomia, Binongko that together with other smaller islands make up the Tukang Besi Archipelago. Surveys were carried out at seven sites near Kaledupa and Hoga islands in July and August 2008 (see Fig. 1). The WMNP is the second largest marine national park in Indonesia and is located within the 'coral triangle' and has exceptional diversity and abundance of scleractinian corals [24]. The WMNP is a suitable location to study the impacts of the loss of hard 
coral on sponge assemblages as it contains some of the most pristine reefs in the world, but also a number of reefs that are heavily degraded as a result of human activities [25]. A rapid ecological assessment carried out in 2003 recorded 396 species of hard coral and 590 species of fish in the park [26], however, there are approximately 90,000 people who inhabit the park and balancing the needs of a growing population with conservation is a major challenge for park authorities and conservation groups.

Site 1 (Buoy $3 ; 05^{\circ} 28.40 \mathrm{~S}, 123^{\circ} 45.45 \mathrm{E}$ ) is a fringing reef on the Western side of Hoga island. It has a reef flat located between $0-4 \mathrm{~m}$ leading to the reef crest which is located 150 $\mathrm{m}$ offshore at a depth of 2-6 $\mathrm{m}$. The reef slope is characterised by walls, overhangs and caves and descends to a depth of approximately $60 \mathrm{~m}$ before levelling out into sandy habitat. Site 2 (Pak Kasims; $05^{\circ} 27.569 \mathrm{~S}, 123^{\circ} 45.179 \mathrm{E}$ ) is located $500 \mathrm{~m}$ north of Buoy 3 on the same fringing reef, however, the reef crest is located further offshore $(\sim 200 \mathrm{~m})$ than Buoy 3 and the reef slope is less vertical, descending at an angle of 40-70 degrees leading to gently sloping sand flats at approximately $50 \mathrm{~m}$. Site 3 (Ridge $1 ; 05^{\circ} 26.565 \mathrm{~S}$, $123^{\circ} 45.138 \mathrm{E}$ ) is situated over $1 \mathrm{~km}$ offshore to the north west of Hoga island. The ridge runs from north to south and has a crest between $4-10 \mathrm{~m}$ wide at a depth of $5-10 \mathrm{~m}$. The reef slopes away on either side of the crest at approximately 70 degrees to over $100 \mathrm{~m}$ on the outer slope and slightly shallower on the inner side. Site 4 (Karang Gurita $\left(05^{\circ} 23.48 \mathrm{~S}, 123^{\circ} 40.37 \mathrm{E}\right)$ is a submerged atoll located off to the south east of Wanci Wanci island. The angle of the reef slopes varies between 45-70 degrees. Site 5 (Kaledupa; $05^{\circ} 28.22 \mathrm{~S}, 133^{\circ} 43.37 \mathrm{E}$ ) is a fringing reef off the island of Kaledupa. The reef slopes at an angle of around 50 degrees to approximately $50 \mathrm{~m}$ where it turns into a sandy slope. It has extensive reef flats characterised by coral bommies, boulders and soft corals. Site 6 (Sampela 1; 05 29.6S, $123^{\circ} 45.26 \mathrm{E}$ ) is located approximately $2 \mathrm{~km}$ south of the Kaledupa study site on the same fringing reef that surrounds Kaledupa island. The reef flat occurs at $2-4 \mathrm{~m}$ and leads to a crest at $1-3 \mathrm{~m}$. The reef slope descends at approximately 45 degrees to between $11-14 \mathrm{~m}$ where it levels off into sand flats. Sampela 1 is situated near to a Bajo village that is built above the reefs flats approximately $400 \mathrm{~m}$ offshore. This reef is considered to be highly degraded with low hard coral species richness and percentage cover compared to other reefs in the park [25]. The reef at Sampela 1 also experiences high levels of sediment, approximately four times higher than those at the Kaledupa study site [25]. The final site, site 7, (Sampela 2; $05^{\circ} 29.3 \mathrm{~S}, 123^{\circ} 45.1 \mathrm{E}$ ) is $200 \mathrm{~m}$ north of Sampela 1 on the same stretch of shallow fringing reef. The topography and environmental conditions of this site are very similar to Sampela 1.

\section{Surveys of Sponge Abundance}

The abundance of sponges was quantified at each site using a divided $0.5 \times 0.5 \mathrm{~m}^{2}$ quadrat at a depth of $10 \mathrm{~m}$. An equal number of quadrats were surveyed on flat $(\sim 0)$, inclined ( 45) and vertical ( $\sim 90)$ surfaces. In total 147 quadrats were surveyed, 21 at each site with 7 on each surface angle. The total number of individual sponge patches was recorded in situ. Photographs were also taken of each quadrat using a Canon G9 camera with underwater housing.

\section{Photo Quadrats}

Photos were analysed to estimate the percentage cover of sponges relative to other major components of the reef benthos. Photos were analysed with Coral Point Count with Excel extensions (CPCe) using a random point count methodology [27]. A matrix of 50 randomly distributed points was overlaid on each quadrat image and the substrate type lying under each was visually identified. The categories used were: sponge, branching hard coral, encrusting hard coral, massive hard coral, sub-massive hard coral, foliose hard coral, tabulate hard coral, free-living hard coral, soft coral, gorgonians, coralline algae (CCA), algae, 'others' (including ascidians, zooanthids, bryozoans, Millepora), recently dead coral (dead coral substrate but the structure is still intact), rock, rubble, and sand.

\section{Data Analysis}

Kolmogorov-Smirnov tests were used to determine whether data were normally distributed. As data were found to be significantly different from normal distributions, nonparametric or semi-parametric tests were used throughout. Univariate and multivariate analyses were carried out using the statistical package PRIMER-E v6 (Plymouth Routines in Multivariate Ecological Research). Analyses were based on similarity matrices calculated using Bray-Curtis coefficients.

A two-factor permutational multivariate analysis of variance (PERMANOVA) [28] was used on the percentage cover data obtained from the photo quadrats to test the null hypothesis that there were no differences in benthic community composition between sites or surface angles. The PERMANOVA incorporated the following factors: (1) Site (random factor with seven levels) and (2) Angle (fixed factor with three levels). Unconstrained non-metric Multi Dimensional Scaling (MDS) and constrained Canonical Analysis of Principal coordinates (CAP) of site percentage cover means were used to graphically represent site differences in two dimensions [29]. Spearman rank correlations of individual benthic components with the resulting CAP axes were used to indicate the benthic groups that characterised the differences among groups from the CAP analysis.

A univariate two-factor PERMANOVA was used to test the null hypothesis that there was no difference in sponge abundance between study sites or surface angles. This test also incorporated the factors (1) Site (random factor with seven levels) and (2) Angle (fixed factor with three levels).

Spearman rank correlations were used to explore the relationship between sponge density and percentage cover and hard coral cover. The mean density of sponges $\left(\mathrm{m}^{-2}\right)$ and the mean hard coral cover (\%) of each of the benthic categories were calculated for site comparisons.

\section{RESULTS}

The benthic assemblages were significantly different between some sites (PERMANOVA, pseudo- $F=5.4966$, $\mathrm{p}<0.001)$. Table 1 summarizes the percentage cover of the major benthic categories at each of the study sites. There was also a significant difference between the benthic communities on different surface angles (PERMANOVA, pseudo$F=2.7773, \mathrm{p}=0.007)$ and also a significant interaction bet- 
Table 1. Percentage Cover of the Major Benthic Categories at the Study Sites Ranked from Highest to Lowest Coral Cover

\begin{tabular}{|c|c|c|c|c|c|c|c|c|c|c|c|}
\hline \multirow{2}{*}{ Site } & \multicolumn{11}{|c|}{$\%$ Cover } \\
\hline & Coral & Sponges & Soft coral & Gorgonians & Algae & CCA & Others & Dead coral & Rock & Rubble & Sand \\
\hline Buoy 3 & 51 & 4 & 5 & 0 & 7 & 8 & 3 & 1 & 21 & 0 & 0 \\
\hline Ridge 1 & 31 & 11 & 9 & 1 & 13 & 8 & 1 & 3 & 21 & 1 & 1 \\
\hline Karang Gurita & 28 & 7 & 9 & 0 & 13 & 15 & 1 & 2 & 17 & 5 & 3 \\
\hline Pak Kasim's & 27 & 3 & 14 & 0 & 11 & 12 & 0 & 4 & 19 & 10 & 0 \\
\hline Sampela 1 & 13 & 8 & 5 & 0 & 22 & 9 & 2 & 4 & 32 & 3 & 2 \\
\hline Kaledupa & 9 & 7 & 23 & 1 & 23 & 8 & 1 & 1 & 24 & 2 & 1 \\
\hline Sampela 2 & 3 & 7 & 6 & 0 & 33 & 14 & 1 & 0 & 27 & 4 & 5 \\
\hline
\end{tabular}

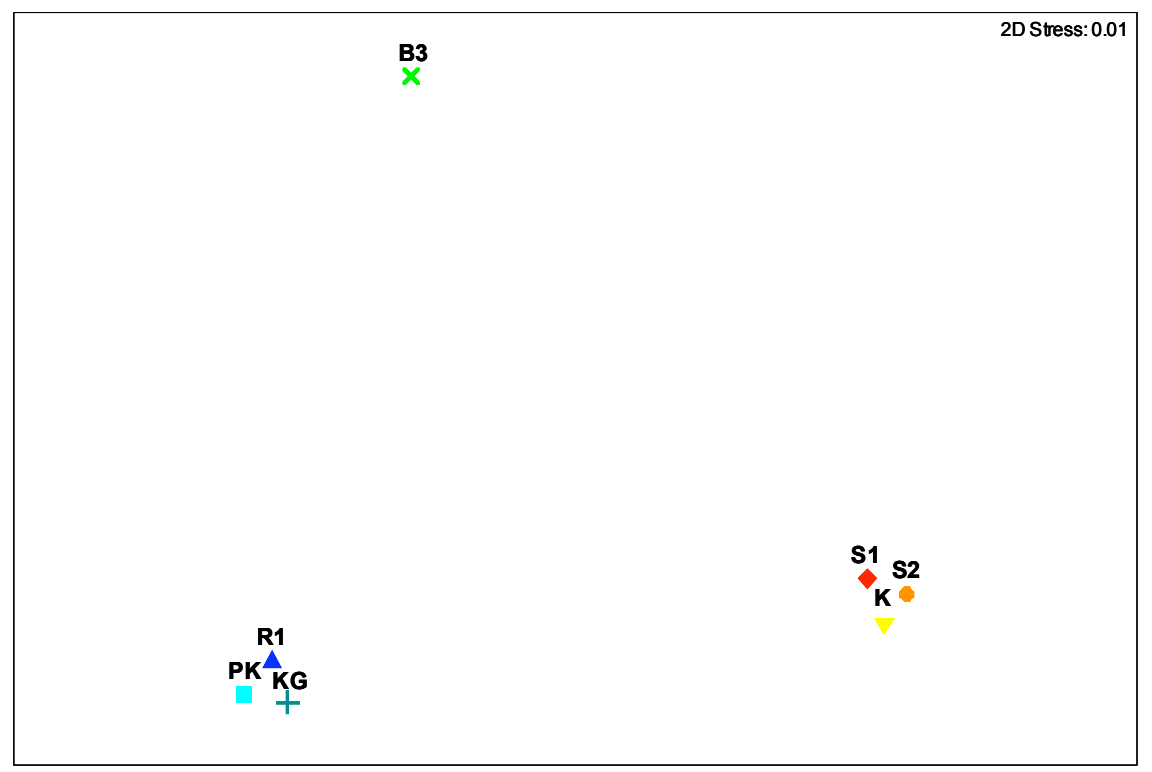

Fig. (2). MDS ordination showing similarities in benthic composition between sites. The ordination is based on a Bray-Curtis similarity matrix of site percentage cover means.

ween site and surface angle (PERMANOVA, pseudo$F=1.7593, \mathrm{p}=0.001)$. The unconstrained MDS ordinations showed similarity among assemblages at some sites (Fig. 2). The higher coral cover sites (Pak Kasims, Karang Gurita and Ridge 1) were grouped. The sites with lower hard coral cover (Sampela 1, Sampela 2 and Kaledupa) form another group; Buoy 3 was different from all the other sites. The constrained CAP ordination showed similar grouping of sites to the unconstrained MDS plot. The vectors superimposed on the CAP ordination indicate that Sampela 1, Sampela 2 and Kaledupa are characterised by sponges, rock, algae and sand. Ridge 1, Karang Gurita and Pak Kasims were characterised by hard coral, and particularly by branching, sub-massive, encrusting, foliose, massive and tabulate growth forms. Buoy 3 was characterised by 'others' which mainly consisted of ascidians and high hard coral cover (Fig. 3).

A significant but weak positive correlation was found bet-ween sponge density and percentage coral cover (Spearman's rank correlation $\mathrm{r}=0.184$, d.f $.=146, \mathrm{p}=0.026$ ) (Fig. 4). Sponge density varied between the study sites (see Fig. 5) with the highest density ( $\pm \mathrm{SE}$ ) being reported at Buoy 3 (160 sponges $\mathrm{m}^{-2} \pm 32$ ) and the lowest at Sampela 2 (84 sponges $\left.\mathrm{m}^{-2} \pm 12\right)$. The univariate two-factor PERMANOVA indicated that there was a significant difference in sponge density between the sites ( sseudo- $F=2.7801, \mathrm{p}=0.002$ ), but there was no significant difference in the number of sponges on different surface angles ( $p$ seudo- $F=1.3779, \mathrm{p}=0.299$ ). In contrast, we found a weak but significant negative correlation between sponge percentage cover and hard coral cover (Spearman's rank correlation $\mathrm{r}=-0.181$, d.f. $=146, \mathrm{p}=$ $0.028)$. We found no significant difference in the percentage cover of sponges between the study sites.

\section{DISCUSSION}

This study examined how sponge densities and percentage cover varied between seven sites in the WMNP in relation to other major benthic organisms and substrate types. The relationship between hard coral cover and sponge abundance is of particular interest due to current concerns 

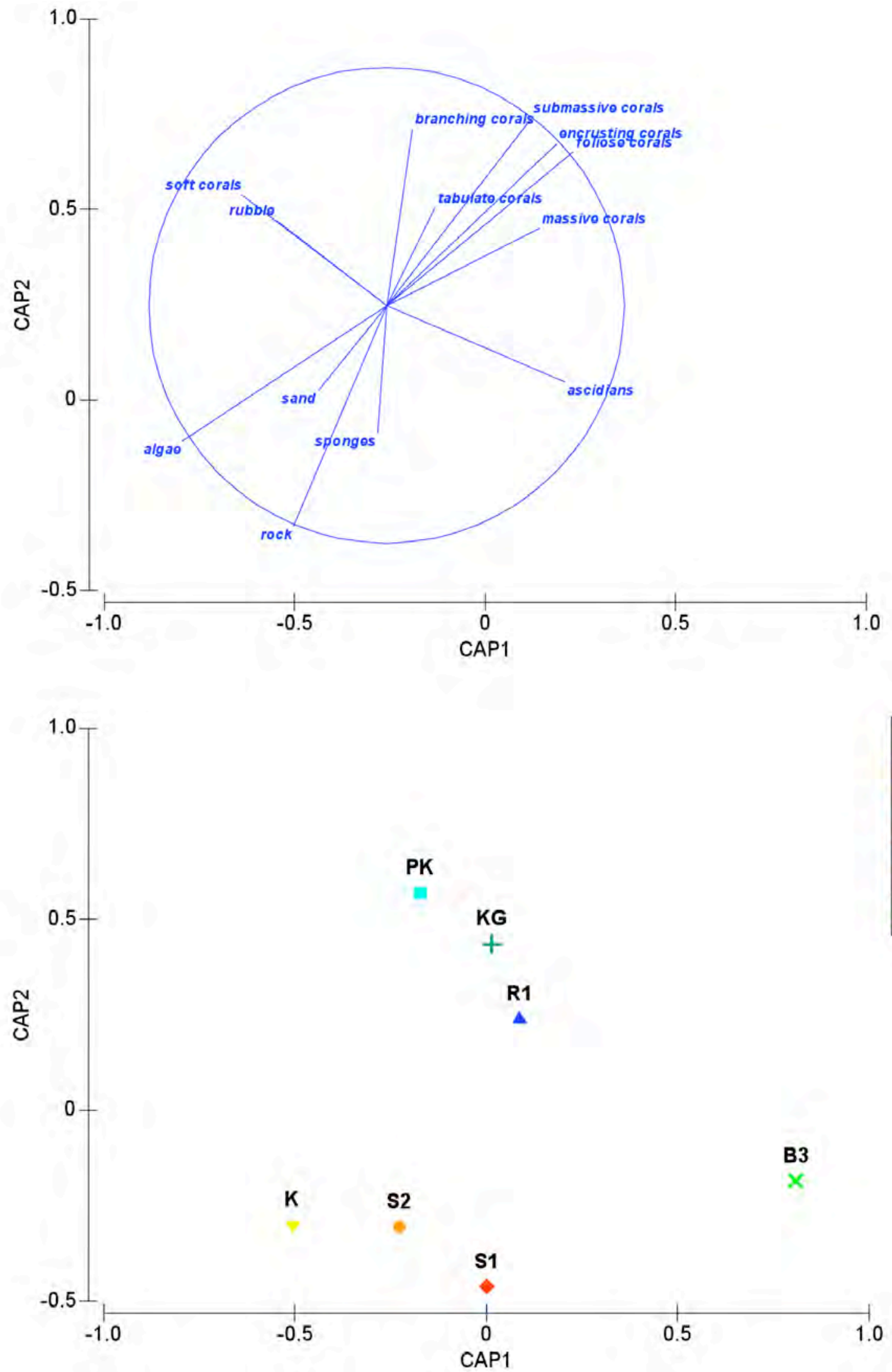

Fig. (3). a) CAP ordination showing similarity between sites. The ordination is based on a Bray-Curtis similarity matrix. b) Vectors represent Spearman rank correlations of individual variables with the CAP axes (restricted to those having lengths $>0.4$ ) indicating which variables characterise the different study sites. 


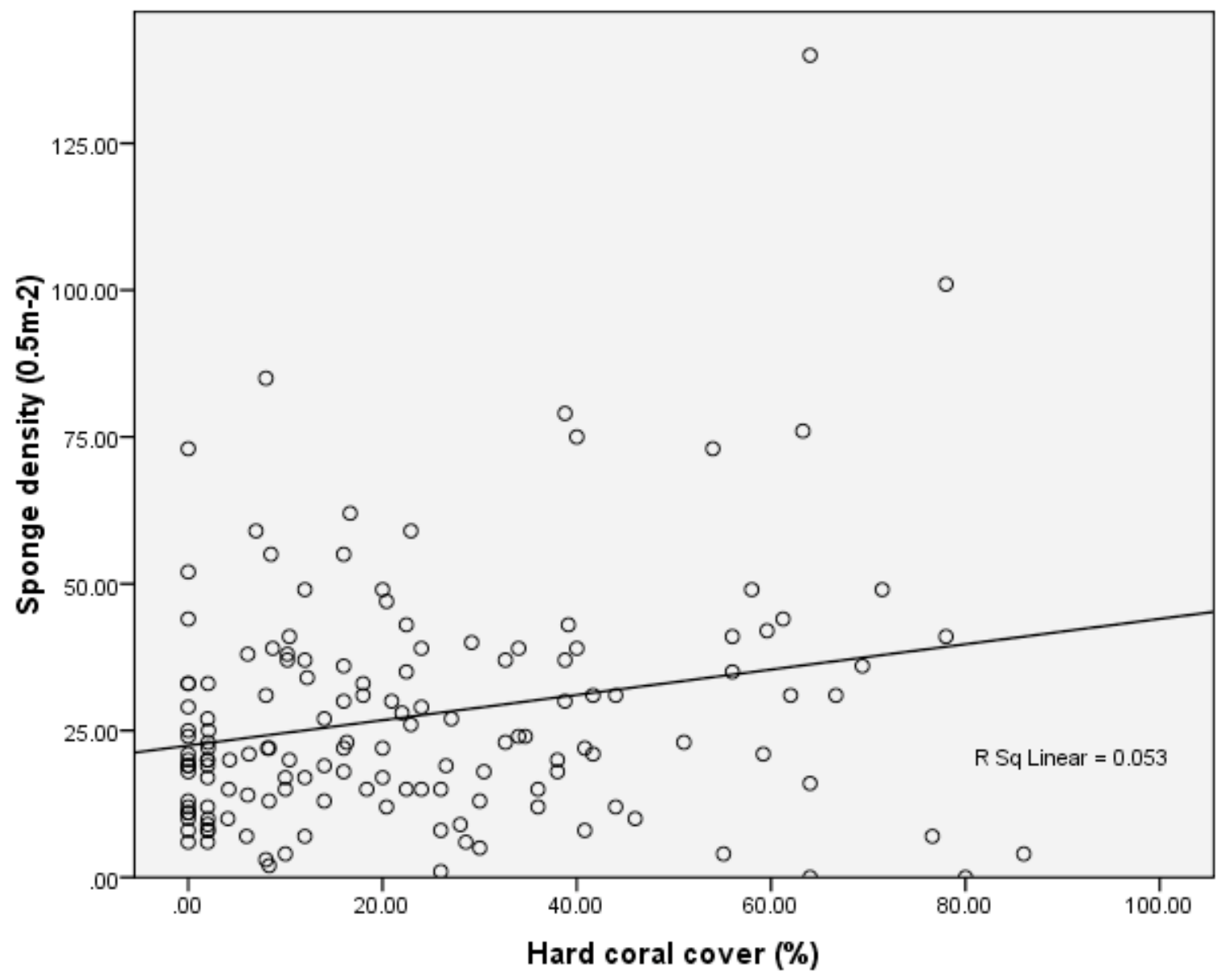

Fig. (4). The relationship between mean sponge density $\left(0.5 \mathrm{~m}^{-2}\right)$ and mean hard coral cover $(\%)$.

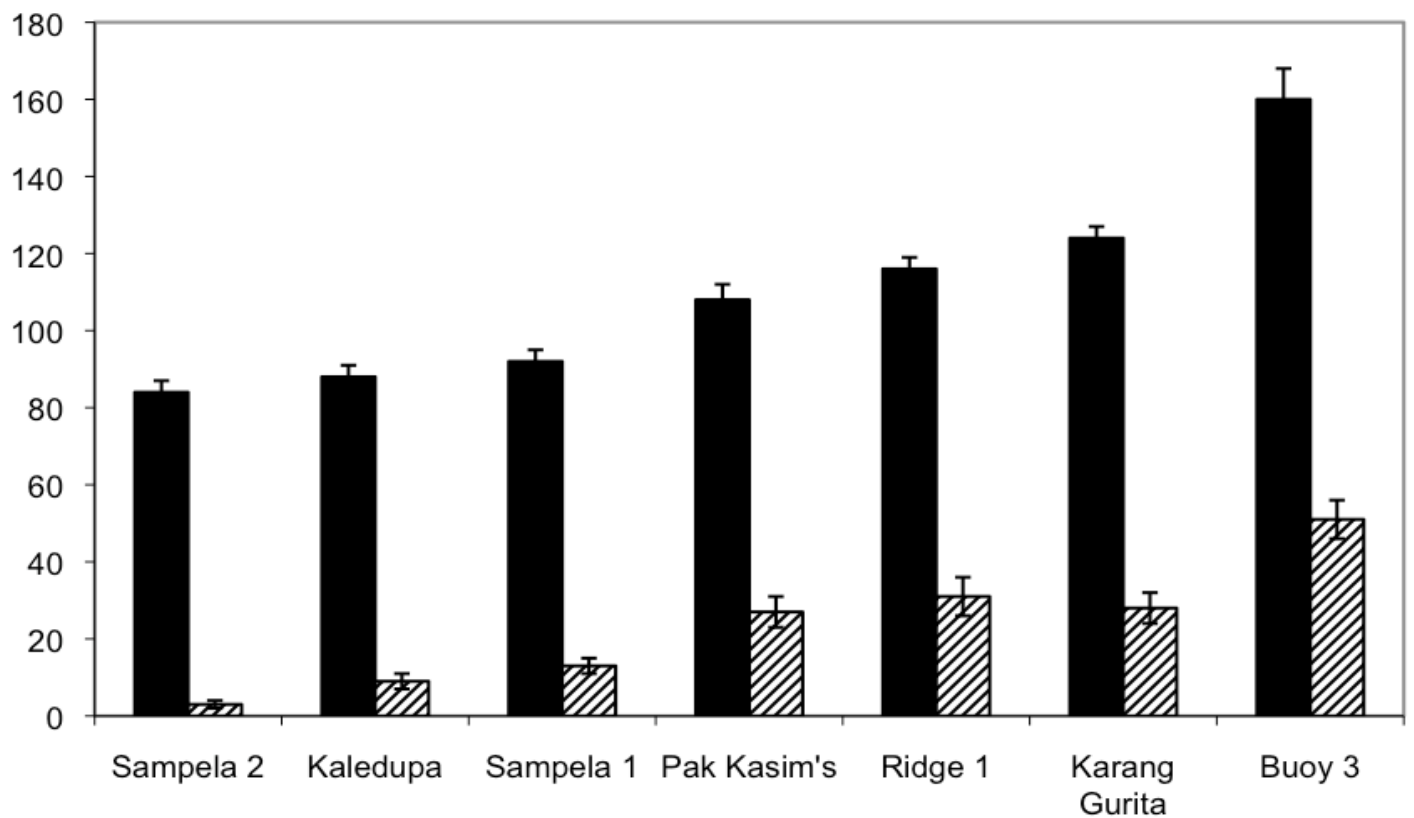

Fig. (5).

Mean sponge density $\mathrm{m}^{-2}$ at the seven study sites.

Mean coral cover at the study sites. 
over the loss of hard coral on many Indo-Pacific reefs and how this may influence other organisms. The results of this study contradict our hypothesis that sponge densities would be negatively correlated with hard coral cover as we found a weakly significant positive correlation between sponge abundance and coral cover. We also found a similar pattern when we compared mean sponge densities and mean hard coral cover at the study sites. Sites with higher mean hard coral cover had higher mean sponge densities and conversely sites with lower mean coral cover had lower sponge densities.

One explanation for the relationship between percentage cover of coral and sponge density is that increasing hard coral provides a greater number of micro-habitats for sponges to occupy (e.g. amongst the Acropora branches). The majority of the sponges found in the WMNP are small and cryptic, and are found on almost all available substrate types including the undersides of foliose corals and on the skeletons of recently dead corals. Sites with high coral cover had higher levels of recently dead corals than lower coral cover sites (since coral died some time ago), which may also explain our results.

It is also possible that environmental variability between sites may explain the lower sponge densities at some sites. At Sampela 1 and Sampela 2, sedimentation is of particular interest. Both of these sites have low coral cover and also experience high levels of sediment loading. Sedimentation is known to have a number of detrimental effects on corals, but can also have a negative effect on some sponge species [30]. In this study it is difficult to differentiate between the effects of reduced coral cover and sedimentation at Sampela 1 and 2. It is possible that the lower sponge densities at the Sampela study sites are a result of high levels of sedimentation, rather than lower coral cover.

Alternatively, there may be another factor preventing an increase in sponge densities at low coral cover sites. Despite the fact that some sponges produce toxic secondary metabolites they are known to be an important component of the diet of some reef fish, particularly angelfish [31]. A number of studies have shown that fish predation can affect sponge diversity and abundance on Caribbean reefs $[17,32]$. In addition to limiting the distribution of certain species, caging experiments in the Florida Keys have also shown that predation can influence sponge competitive abilities. Excluding predators from naturally occurring sponge-coral interactions resulted in a significant decrease in coral cover compared to uncaged interactions [33]. These results indicate that direct and indirect effects of predation on sponges may have considerable effects on species diversity on Caribbean reefs. Levels of fish predation on sponges in Indonesia are unknown but given its effects in the Caribbean they are likely to have an impact on sponge densities and could be limiting densities at lower coral cover sites in the IndoPacific.

In our study we found that substratum angle had an effect on overall benthic composition, but did not find any effect on sponge densities. Substratum angle is known to influence sponge densities in temperate regions and in 2004 Bell \& Smith found higher numbers of sponges on horizontal, inclined and vertical surfaces respectively at Sampela which they attributed to less sediment settlement on vertical sur- faces. Qualitative observations suggest that increases in the abundance of the encrusting sponge species Dysidea spp. since 2002 may explain why no significant differences were found between surface angles. This sponge was very abundant on horizontal surfaces at Sampela and has photosynthetic symbionts which may explain its abundance on well illuminated hortizontal surfaces despite the sedimentation at this site.

Our results do support our hypothesis that the percentage cover of sponges would be negatively correlated with hard coral cover. This result suggests that although quadrats with lower hard coral cover generally had fewer sponges in them the sponges that did grow there had a greater surface area. Without species information it is impossible to say whether the species that occur in the low coral areas are different to the ones that occur in high coral cover areas. Unlike sponge densities we did not find a significant difference in sponge percentage cover between the study sites due to the high levels of variability.

Multivariate analysis revealed a significant difference in the overall benthic composition between some sites. The results of the CAP ordination showed that the higher quality sites (such as Buoy 3, Karang Gurita and Ridge 1) were characterised by hard corals and that the more degraded sites are characterised by sponges. This was surprising given that we did not find any significant difference between the sponge cover (\%) at the study sites. However, at the degraded sites the proportion of sponge was higher than at the higher quality sites. This finding is significant because it raises the possibility that as a site becomes degraded it may switch from being characterised by hard coral to being characterised by sponges. This can occur even if the percentage cover or number of sponges does not increase when hard coral cover is reduced. A long-term study of shifts in community structure of sponges and corals in permanent quadrats on coral reef slopes in the Caribbean found that despite the fact that $78 \%$ of the sponges initially present in 1977 died during the first five years of the study, overall sponge percentage cover and densities remained remarkably stable despite a major reduction in the percentage cover and density of corals due to smothering by macro algae [34].

In contrast, other recent studies have examined temporal changes in tropical sponge assemblages and found changes in sponge abundance over time. A 14 year study of sponges on a shallow reef in Panama revealed a steady disappearance of sponge species over the study period possibily due to sponge disease [35]. The results of a six year study in Mexico found short-term and long term fluctuactions in sponge densities as a result of seasonal changes in wind patterns and large-scale structuring factors such as the El Niño Southern Oscillation [36]. These contrasting results indicate that the factors controling sponge densities are likely to vary on different reef systems.

In conclusion, we found that sponge densities are weakly positively correlated with hard coral cover whereas sponge percentage cover is weakly negatively correlated with hard coral cover. These differences may be due to the occurrence large numbers of small sponges in high coral cover areas and lower numbers of larger sponges in low coral cover areas. The weak nature of these correlations suggest that while spatial competition is partially responsible for determining 
sponge densities and percentage cover in the WMNP other factors such as fish predation and other environmental conditions may play a key role and are important areas for future research.

\section{ACKNOWLEDGEMENTS}

Operation Wallacea, Commonwealth Scholarship and Fellowship Plan, Education New Zealand, Singapore Airlines, Matthew Fynes, the staff of Hoga Island Marine Research Station.

\section{REFERENCES}

[1] Wilkinson C, Ed. Status of coral reefs of the world. Townsville: Australian Institute of Marine Science 2004, Vol. 2.

[2] Hughes TP. Catastrophes, phase shifts, and large-scale degradation of a Caribbean coral reef. Science (U.S.) 1994; 265: 1547-51.

[3] Pandolfi JM, Bradbury RH, Sala E, et al. Global Trajectories of the Long-Term Decline of Coral Reef Ecosystems. Science 2003; 301: 955-8.

[4] Rogers CS. Degradation of Caribbean and Western Atlantic coral reefs and decline of associated fisheries. Proceedings of the fifth International Coral Reef Congress, Tahiti 1985; Vol. 6: pp. 491-6.

[5] Graham NAJ, Wilson SK, Jennings S, Polunin NVC, Bijoux JP, Robinson J. Dynamic fragility of oceanic coral reef ecosystems. Proc Natl Acad Sci USA 2006; 103(22): 8425-9.

[6] Lesser MP. Coral reef bleaching and global climate change: Can corals survive the next century? Proc Natl Acad Sci USA 2007; 104(13): 5259-60.

[7] Tkachenko KS, Wu BJ. et al. Dynamics of a coral reef community after mass mortality of branching Acropora corals and an outbreak of anemones. Mar Biol 2007; 151(1): 185-94.

[8] Fitt WK, Brown BE, Warner ME, Dunne RP. Coral bleaching: interpretation of thermal thresholds in tropical corals. Coral Reefs 2001; 20: 31-65.

[9] Barthel D, Gutt J, Tendal OS. New information on the biology of Antarctic deep-water sponges derived from underwater photography. Mar Ecol Prog Ser 1991; 69(3): 303-7.

[10] Bell JJ, Barnes DKA. A sponge diversity centre within a marine 'island'. Hydrobiologia 2000; 440: 55-64.

[11] Diaz MC, Rutzler K. Sponges: An essential component of Caribbean coral reefs. Bull Mar Sci 2001; 69(2): 535-46.

[12] Wulff J. Assessing and monitoring coral reef sponges: Why and how? Bull Mar Sci 2001; 69(2): 831-46.

[13] Bell JJ. The functional roles of marine sponges. Est Coast Shelf Sci 2008; 79(3): 341-53.

[14] Bell JJ, Smith D. Ecology of sponge assemblages (Porifera) in the Wakatobi region, south-east Sulawesi, Indonesia: Richness and abundance. J Mar Biol Assoc UK 2004; 84(3): 581-91.

[15] de Voogd NJ, Cleary DFR. Relating species traits to environmental variables in Indonesian coral reef sponge assemblages. Mar Freshw Res 2007; 58(3): 240-9.

[16] Suchanek TH, Carpenter RC, Witman JD, Harvell CD. Sponges as important space competitors in deep Caribbean coral reef communities. In: Reaka ML, Ed. The ecology of deep and shallow coral reefs \%7 Symposia series for undersea research. Rockville, Maryland: NOAA 1983: 55-60.

[17] Wulff JL. Trade-offs in resistance to competitors and predators, and their effects on the diversity of tropical marine sponges. J Anim Ecol 2005; 74(2): 313-21.

[18] Aerts LAM. Sponge/coral interactions in Caribbean reefs: analysis of overgrowth patterns in relation to species identity and cover. Mar Ecol Prog Ser 1998; 175: 241-9.

[19] Bell JJ, Barnes DKA. The importance of competitor identity, morphology and ranking methodology to outcomes in interference competition between sponges. Mar Biol 2003; 143(3): 415-26.

[20] Jackson JBC, Buss L. Allelopathy and spatial competition among coral reef invertebrates. Proc Natl Acad Sci USA 1975; 72: 5160-3.

[21] Becerro MA, Turon X, Uriz MJ. Multiple functions for secondary metabolites in encrusting marine invertebrates. J Chem Ecol 1997; 23: $1527-47$.

[22] Aerts LAM. Dynamics Behind Standoff Interactions in Three Reef Sponge Species and the Coral Montastraea cavernosa. Mar Ecol 2000; 21(3-4): 191-204.

[23] de Voogd NJ, Becking LE, Hoeksema BW, Noor A, van Soest RWM. Sponge interactions with spatial competitors in the Spermonde Archipelago. Bollettino dei Musei e degli Istituti Biologici della Universita di Genova 2004; 68: 253-61.

[24] Hoeksema BW. Delineation of the Indo-Malayan centre of maximum marine biodiversity: the coral triangle biogeography, time, and place: distributions, barriers, and islands: Springer: The Netherlands 2007: pp. 117-78.

[25] Crabbe JM, Smith DJ. Comparison of two reef sites in the Wakatobi Marine National Park (SE Sulawesi, Indonesia) using digital image analysis. Coral Reefs 2002; 21(3): 242-4.

[26] Pet-Soede L, Erdmann M, Eds. Rapid Ecological Assessment Wakatobi National Park. November 2003. Report from WWF Indonesia Marine Program, Denpasar, Bali: Indonesia 2004.

[27] Kohler KE, Gill SM. Coral Point Count with Excel extensions (CPCe): A Visual Basic program for the determination of coral and substrate coverage using random point count methodology. Comput Geosci 2006; 32(9): 1259-69.

[28] Anderson MJ. PERMANOVA: a FORTRAN computer program for permutational multivariate analysis of variance. New Zealand: Department of Statistics, University of Auckland 2005.

[29] Anderson MJ, Willis TJ. Canonical analysis of principal coordinates: a useful method of constrained ordination for ecology. Ecology 2003; 84(2): 511-25.

[30] Gerrodette T, Flechsig AO. Sediment-induced reduction in the pumping rate of the tropical sponge Verongia-Lacunosa. Mar Biol 1979; 55(2): 103-10.

[31] Randall JE, Hartman WD. Sponge-feeding fishes of the West Indies. Mar Biol 1968; 1: 216-25.

[32] Dunlap M, Pawlik JR. Spongivory by parrotfish in Florida mangrove and reef habitats. Mar Ecol 1998; 19(4): 325-37.

[33] Hill MS. Spongivory on Caribbean reefs releases corals from competition with sponges. Oecologia 1998; 117(1-2): 143-50.

[34] Hughes TP. Demographic approaches to community dynamics: a coral reef example. Ecology 1996; 77(7): 2256-60.

[35] Wulff LJ. Rapid diversity and abundance decline in a Caribbean coral reef sponge community. Biol Cons 2006; 127: 167-76.

[36] Carballo JL, Vega C, Cruz-Barraza JA, et al. Short- and long-term patterns of sponge diversity on a rocky tropical coast: evidence of large-scale structuring factors. Mar Ecol 2008; 29: 216-36. 